\title{
WALE A.R. SULAIMAN: THE MASTER OF KNOWLEDGE, NEUROSURGERY AND HUMANITY
}

\section{THE DESIRE FOR KNOWLEDGE GUIDES HIM}

Born on 5 September 1970 in Lagos, Nigeria, receiving scholarship from the Bureau for External Aid, a Nigerian government program, Wale Sulaiman came to Varna, Bulgaria in 1991 to study medicine. He worked devotedly as a student research associate in my Laboratory of Electron Microscopy and graduated summa cum laude from Medical University of Varna in 1997.

\section{THE EXECUTOR OF DREAMS}

I have had the privilege to follow his dream: first to defend $\mathrm{PhD}$ thesis in neuroscience followed by training in neurosurgery. Hence, next day after receiving his MD diploma I sent Wale to work on his $\mathrm{PhD}$ thesis at the University of Alberta, Edmonton, Canada. His neurosurgery training was completed at the University of Manitoba, Winnipeg, Canada and his post-residency fellowship training in at Louisiana State University and in spine surgery at the Medical College of Wisconsin in Milwaukee.

And Wale Sulaiman, MD, PhD became Professor of Clinical Neurosurgery, Tulane University, New Orleans, LA, USA* and System Chairman, Department of Neurosurgery, Co-Medical Director, Ochsner Neuroscience Institute, Medical Director of Back and Spine Center Ochsner Health System, and Ochsner's Medical Director of International Medicine for the African Region.

As a consequence of his knowledge and experience, Dr Wale Sulaiman is recognized as one of the best spine surgeons in the USA. He is also skilled in the application of minimally invasive techniques to treat spinal disorders

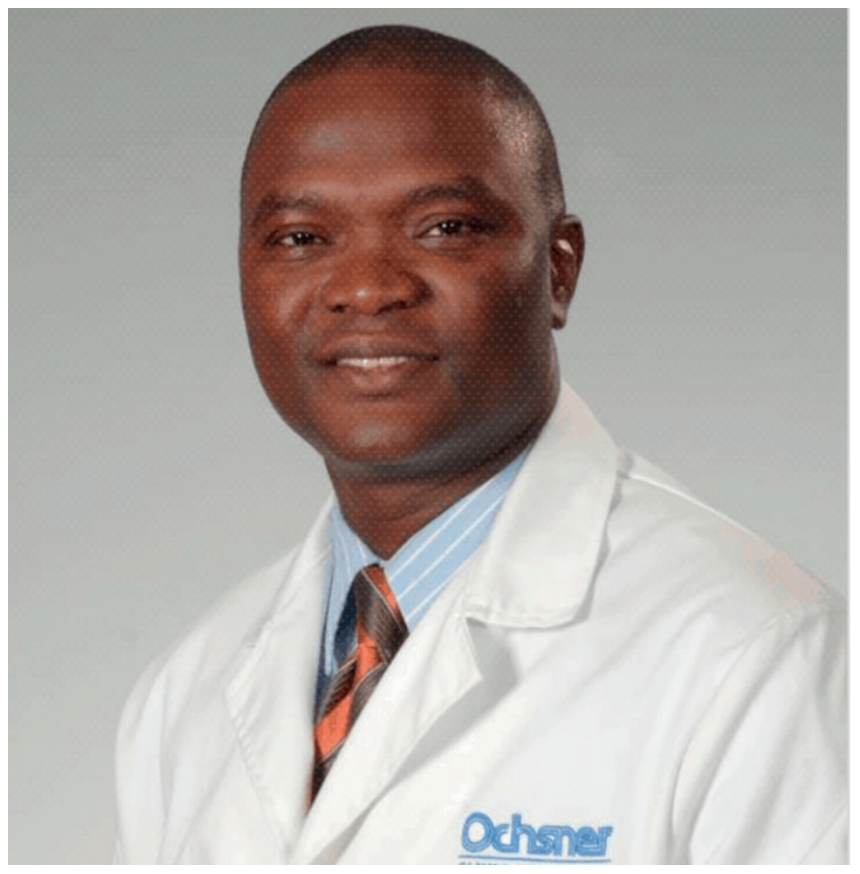

Dr Olawale Sulaiman.

Photo credit: https://anpa.org

(something like "Lazarus, get up and walk!" - Jesus said). He involved creatively in neuroscience research at the Laboratory for Neural Regeneration at Ochsner Medical Center. Altogether, this has earned him recognition locally, nationally, and internationally - we, at Medical University of Varna, being proud of him.

\section{IN PURSUIT OF HIS PHILANTHROPY}

Last 10 years Dr Wale Sulaiman has been dividing his time between the USA and Nigeria to provide affordable healthcare and to often perform surgeries at personal 
expense in his home country - a high level of geomagnetism. Recently, he told $C N N$ that his motivation comes from growing up in the relatively poor region of Lagos: "I am one of 10 children born into a polygamous family. My siblings and I shared one room where we often found ourselves sleeping on a mat on the floor." - Wale said.

During his student years we have had many discussions on different topics. In one of them I told Wale about John McCrae, Canadian physician, Professor of Pathology, and soldier in the First World War. And his philanthropic thought: "Things you give away freely you still possess". Recently, Wale told CNN, "I would use my vacation times for the medical missions, which were also planned with education and training sessions. We donated a lot of medications, equipment and hands-on training on surgical techniques."

\section{THE LEADER OF HEALTHCARE DEVELOPMENT IN AFRICA}

Professor Wale Sulaiman is a renowned leader on the country's healthcare challenges. He acts as an advisor to Nigerian Ministries of health at the state and federal levels. He founded, chaired and is chief executive officer (CEO) of RNZ Global, a leader of healthcare development in sub-Saharan Africa, Wale's wife Patricia Sulaiman as Director of RNZ Global. "There are a tremendous number of brilliant Nigerians in diaspora who will significantly contribute to raising the standard of healthcare in Nigeria." - Dr Sulaiman said.

Furthermore, via his RNZ Foundation, which is the not-for-profit arm of RNZ Global, he is providing scholarships for university education, renovations of primary and secondary schools, funding of youth centres for recreational activities and sports, also other philanthropic activities. This remind me the philanthropy of Drs Mayo, father and his two sons, in Rochester, MN, USA, including the support of Mayo Foundation
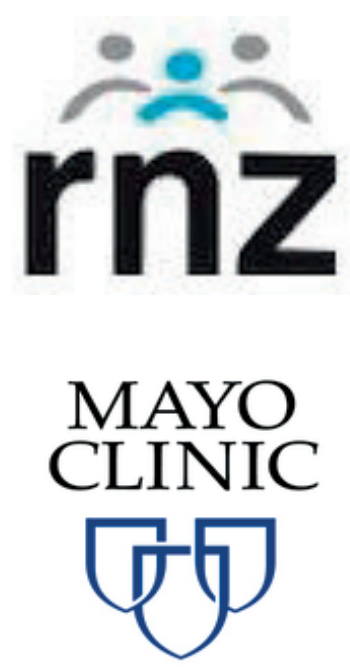
to lecture at the Rochester International Angiology Congress held in 1983.

We do believe in Wale A.R. Sulaiman's power of knowledge, skills and humanity and his commitment to "bring excellent healthcare service back to Nigeria", as his wife said.

George N. Chaldakov Editor-in-Chief, Biomedical Reviews

*Invited by Professor Jack P. Strong, Head of Department of Pathology, Louisiana State University, New Orleans, LA, I have received Eligibility document for my appointment on July 1974 as Visiting Research Fellow at Dr Strong's Department to work on atherogenesis. Unfortunately, the communistic regime did not allow me to pursue my dream. Fortunately, Wale did that! 